\title{
Исследовательская рефлексия
}

\section{«Я ничем вам не помог...": исследовательская рефлексия вслед неудачному интервью}

DOI: 10.19181/inter.2020.21.5

Ссылка для цитирования:

Омельченко Е.Л. «Я ничем вам не помог...»: исследовательская рефлексия вслед неудачному интервью // Интеракция. Интервью. Интерпретация. 2020. Т. 12. № 1. С. 81-95. DOI: https://doi.org/10.19181/inter.2020.21.5.

For citation:

Omelchenko E. L. (2020) "I didn't help you in any way...": Research Reflection After a Failed Interview. Interaction. Interview. Interpretation. Vol. 12. No. 1. P. 81-95. DOI: https://doi.org/10.19181/ inter.2020.21.5.

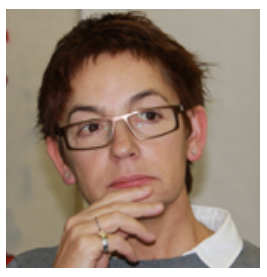

Елена Омельченко *

В статье обсуждаются сложные и критические моменты сопряжения и/ или рассогласования этических и профессиональных принципов и навыков работы социолога в ходе реализации проектов, обращенных к трудным, сенситивно нагруженным полям. Баланс допустимых границ вторжения в личные пространства информантов, соблюдение принципов добровольности могут в процессе интервью начать конфликтовать с проектными обязательствами исследователя, возможные риски для информанта - с сохранением безопасного (физического, психологического) пространства интервьюера. Этот конфликт рассматривается как часть эмоциональной работы социолога в ходе непосредственной коммуникации с информантами, а также переживаний и рефлексий, предшествующих и следующих за беседой, оставляющих след в профессиональной идентичности социолога в целом. В статье критически осмысливаются допустимые пределы беспристрастности исследователя, способности разводить личное и профессиональное «Я» в изучении уязвимых (зависимых) групп и индивидов, находящихся в трудной жизненной ситуации. В данной статье речь идет

* Омельченко Елена - доктор социологических наук, профессор, директор Центра молодежных исследований, Национальный исследовательский университет «Высшая школа экономики» в Санкт-Петербурге, omelchenkoe@mail.ru. 
об изучении жизненного опыта тех, кто проходит реабилитацию (физическую, психологическую, социальную) в одном из общественных центров (НКО) помощи людям, недавно освободившимся из местных колоний и оказавшимся в крайней степени социального одиночества.

Ключевые слова: эмоциональная работа; сенситивное поле; жизненный опыт; изучение уязвимых групп

Эта статья-эссе обращена к моему недавнему полевому опыту1. Эмпирическим материалом работы станет как сам текст одного интервью, взятого в экспедиции, так и мои рефлексии, эмоции, впечатления и воспоминания, сопровождавшие беседу и не отпускающие до сих пор. Полевой этап этого проекта только начинается, анализ ключевых задач проекта в отдаленном будущем. В фокусе этой статьи-эссе - не только вопросы эмоциональной работы в сложном сенситивном поле. Важными станут размышления о том, каковы критерии удачного и неудачного интервью. Что, кроме развернутых плотных нарративов информанта, можно отнести к исследовательскому материалу помимо «классических» дневниковых заметок «на полях»? Становится ли мой собственный опыт проживания беседы частью полученного материала? В какой момент стоит, и стоит ли, отказываться от проведения интервью или останавливать его? Не превращаются ли подобные беседы в факт прямого использования человека, находящегося в зависимой ситуации, что ставит под сомнение сам принцип добровольности? Это лишь часть тех вопросов, ответы на которые я ищу.

В очередной раз убедилась, что никакой опыт полевых исследований и успешное проведение самых разных интервью (от коротких до десятичасовых) не может служить гарантом, что ты в какой-то момент не сорвешься и не допустишь самых элементарных ошибок. После чего ты переживешь катарсис со знаком минус, переходящий в ночные кошмары с бесконечно повторяющимися в голове ошибками, промахами, стыдными оплошностями и сомнительными репликами, допущенными в интервью этого дня². Разбор подобных ситуаций всегда полезен. Очень сложно быть предельно честной и откровенной. Но в этот раз мне этого особенно хочется.

Ситуация. Исследование посвящено глубинному анализу тюремного опыта людей, недавно освободившихся из российских колоний. Это уже третий заход в это сложное поле ${ }^{3}$. Как и всегда, мы старались рекрутировать максимально вариативный охват информантов: мужчин и женщин, молодых и не очень, «одно-» и «многоходовых», с разными сроками и по разным статьям. На этот раз полевой этап проходил в одном из сибирских

\footnotetext{
1 Это пилотажный этап инициативного проекта, реализуемого группой социологов.

2 Одна из последних интересных статей, посвященных эмоциональной работе в поле: (Гудова, 2019).

3 По результатам двух проектов, посвященных женскому опыту тюремного заключения, были опубликованы книги: (До и после тюрьмы..., 2012; Около тюрьмы..., 2015).
} 
городов и в районных центрах области. Работали мы командой в формате экспедиции, что предполагало не только интервью, но и наблюдения, ведение полевых записей и дневников, в которых важно было фиксировать как то, что непосредственно сопровождало беседу исследователя и информанта, так и некую атмосферу вместе с более широкой сферой повседневной включенности собеседников.

Итак. Интервью состоялось в одном из реабилитационных центров помощи бывшим заключенным (НКО), организованных бывшим оперативником Сергеем, отсидевшим относительно небольшой срок за превышение полномочий ${ }^{4}$. Сам центр произвел на меня одновременно и удручающее, и вдохновляющее впечатление. На самом краю города - районного центра области, в промзоне, перемешанной с остатками частного сектора, в ветхом, но заметно отремонтированном двухэтажном здании, вокруг которого можно было различить хозяйственные постройки (как потом стало понятно - сарай для разведения кроликов) и теплицы, занесенные снегом. При подходе к дому меня встретила стая дворовых собак, две из них впоследствии оказались «своими» - мама и сын-подросток, за которыми ухаживали постояльцы центра... Я прошла через длинный коридор, заваленный вещами и утварью (сюда, как потом выяснилось из разговоров, жители-соседи приносят ставшие им ненужными вещи - одежду, лопаты, посуду, реже - еду). Попала я в этот центр не случайно, уже была достигнута договоренность с его руководителем о рекрутинге информантов - постояльцев (временных или более постоянных), и до меня уже было проведено одно интервью моей коллегой. Это отчасти освободило меня от обязательств объяснения целей проекта и всей сопутствующей процедуры получения информированного согласия на проведение исследования в этом месте. Также была достигнута договоренность о помощи в рекрутировании от руководителя центра. Я еще раз подтвердила, что мы гарантируем полную конфиденциальность и последующую анонимизацию полученного материала, который будет использован исключительно в научных целях.

Сергей сказал, что сейчас позовут обещанного мне информанта, но надо немного подождать. Информант, по его словам, отказывается от помощи, идет со второго этажа сам, идет медленно, потому что идти практически не может. «У нас тут здоровых и не бывает, к нам попадают уже те, кому идти по большому счету некуда. Кому они такие, еще и больные, нужны...» Пока я жду, Сергей рассказывает, что мой собеседник только что появился у них в центре, его «отпустили из колонии» по причине тяжелой болезни, лечить которую уже практически невозможно (острый артрит коленей, крайне запущенная болезнь вен, туберкулез). Насколько точен факт - не знаю, но, по его словам, этого мужчину отпустили до окончания срока. Пока жду беседы - говорим с ним о центре: как устроен, как появился, откуда сама идея, ну и как получается содержать от 30 до 40 пациентов - кормить, одевать,

4 Руководитель этого центра Сергей (имя изменено) сам рассказал мне об этом факте своей биографии. С Сергеем не велась аудиозапись интервью, наша беседа воспроизведена по записям в дневнике. 
мыть, ухаживать (лечить, поддерживать гигиену тела), соблюдать порядок, обеспечивать безопасность.

История такая. Оказывается, это только для меня и коллег по экспедиции этот центр выглядит как некий эксклюзив, таких или подобных организаций пусть и немного, но они есть, особенно в тех местах, где до сих пор сохранилось много действующих тюрем (СИЗО) и колоний. Прямой статистики на предмет того, какой процент освободившихся остается близко («рядом») с колонией, я не видела, поэтому трудно сказать - много их или мало. Но мужчины и женщины, отбывавшие наказание в местных колониях и освободившиеся из заключения, скажем так, достаточно часто остаются рядом, здесь же. Кому-то некуда ехать, кого-то давно никто не ждет в когда-то бывших родными местах, кто-то решает немного «прийти в себя, в форму», прежде чем куда-то возвращаться. Это особая ситуация соседства, характерная для окраин районных центров, подобных тому, где мы были: встретить в этих местах бывших заключенных совсем несложно. Те, кто не был «согрет» помощью и поддержкой во время отсидки, чаще всего остаются рядом с колонией. Те, кто и в тюрьме поддерживал связь с домом, с родными или пользовался особыми привилегиями, был(а) включен(а) в неформальную иерархию, поддерживаемую общаком, может, и не уезжали совсем далеко, но все-таки, скорее, обосновывались в областных центрах.

В центр, где мне предстояло провести интервью, попадали те, у кого никого нет, кого никто не ждал после освобождения, не встречал у ворот, не радовался встрече. Коллектив центра совсем минимальный - руководитель, два или три помощника (тоже из бывших), несколько раз в неделю приходят монашки из лютеранской церкви и из православного прихода - делают перевязки, меняют памперсы, читают книги, молятся вместе. По словам Сергея - у них своего рода коммуна. Те, кто не болеет, кто не лежачий, у кого не самые тяжелые физические проблемы, ухаживают за тяжелыми. Повар - тоже бывшая заключенная, каждый день встает в пять утра и готовит на всех. Сергей пожаловался, что его подопечные отказываются есть кроличье мясо, просят чего-то жирного и непостного (того, что не напоминало бы тюремную еду). Поэтому кролики, которых они разводят, идут для себя и на продажу. Но зато кроличье хозяйство - это рабочие места для двух человек из постояльцев, которые чистят, кормят, ухаживают за животными. Овощи, которые они выращивают в теплицах и парниках с весны и до поздней осени, тоже не очень популярны, «не привыкшие они к витаминам, не понимают, зачем это сено есть...». Поэтому, говорит Сергей, контингент у них хоть и бедный, но по-своему привередливый. В коммуне строгий режим абсолютной трезвости. «Курят все - пусть выходят на улицу, а пить нельзя. Были случаи, устраивали ночной бардак, даже полицию пришлось вызывать. Тут разговор короткий: пьешь - значит уходишь. Сразу». Контингент, конечно, очень сложный, постоянно меняется, «здесь самые больные и уже совсем немощные - типа как на передержке... Мы им документы готовим, на медкомиссии возим, чтобы получить инвалидность. А потом - уже в спецпансионат. Там уже - все. Совсем. Там уже доживают 
просто. Все понимают, что там уже последняя инстанция, последний срок. А что делать? Мы тут не можем их вечно держать». Есть и те, кто практически здоров, но такие попадают сюда редко.

Вот такой разговор. Еще раз оговорюсь, что эта беседа была не под запись, я не готовилась к интервью именно с руководителем центра, мы ждали мужчину, который все это время медленно шел к нам со второго этажа. Несколько раз Сергей убегал ему помочь, но сразу возвращался, «нет, говорит - отказывается, говорит сам дойду...» Забегал к нам в кабинет несколько раз щенок-подросток. Сергей рассказал, что в последний раз их собака родила сразу 12 щенков, вот одного только оставили. «Остальных куда?» - спросила. «Куда-куда, туда... А что делать, вот теперь надо его мать быстрее стерилизовать, тоже задача...».

Когда уже мой будущий информант подходил к нашей комнате, я спросила Сергея про грамоты и благодарности, густо представленные на стене. «Да, занимаемся благотворительностью, вот, благодарности дают и места всякие присуждают... я еще и боксерский детский центр открыл, сейчас там ремонт делаю, хочу расширяться». «А на гранты подаете?» - спросила я. «Пытались, я даже во ФСИН обращался, письма писал, на прием записывался. Говорят, пишите заявки, но, говорят, шансы маленькие, тема ваша не в приоритете...».

Зашел Павел 5 . Сергей его спросил - чай будешь? Да, тот ответил. Чай был предложен мне тоже, но я почему-то отказалась. Павел - очень худой мужчина, маленького роста, на вид лет 70, с палкой, на которую он опирался при ходьбе, в спортивном костюме, седой, аккуратно подстриженный ежиком.

Итак, собственно интервью. Что я узнала? Не очень много. Павел - убийца, не серийный, но три раза сидел, и каждый раз за убийство. Ему 54 года, сидел большую часть жизни - с 20 лет. Говорить ему было крайне тяжело. «Расскажите о себе...»- как всегда, самый первый вопрос любого интервью. Лейтмотивом ответов информанта было: «Нечего мне рассказать...».

Сразу стало понятно, что «классический» вариант начала интервью здесь явно не к месту. Информант часто останавливался, он то ли кашлял, то ли плакал, смотрел все время мимо меня куда-то в стену, очень хотел понять (а может быть, мне это только казалось), чего я от него хочу.

Упуская некоторые, совсем незначительные детали и зависавшие паузы, сошлюсь на начальный кусок интервью, который, собственно, и задал общее направление беседы ${ }^{6}$ :

И.: Я - социолог из университета, мы проводим исследования по поводу тюремного опыта... собираем истории про разных людей, вот. Можете как-то представиться, как вас удобнее называть?

P.:... (неразборчиво).

\footnotetext{
5 Имя и любые идентифицирующие детали истории изменены или анонимизированы.

6 Мне показалось уместным оставлять достаточно большие куски беседы, что может помочь понять не только отдельные сюжеты истории, но и саму атмосферу.
} 
И.: Павел?(пауза) Тяжело говорить?

P.: (тишина).

И.: Можете рассказать, что с вами случилось?

P.: Со мной я не знаю че... (тяжело говорит).

И.: Ммм.

Р.: Ноги отрубаются - все. Не могу ни ходить, ни че...

И.: Ммм. А сколько вы сидели?

Р.: Всю жизнь.

И.: Всю жизнь? А за что?

Р.: И за убийство, и за все! (длинная пауза).

И.: А можете что-то рассказать... За что, кого убили?

Р.: Долгая история... убивать.

И.: Ну, это понятно, долгая, у меня время есть послушать.

Р.: Как... че? Как? Конкретно че?

$\cdots$

И.: Ну, когда первый раз сели? Сколько раз сидели?

Р.: Много раз сидел.

И.: Сколько? Пять?

P.: (длинная пауза) По десятке.

И.: По десятке? Что, каждый раз было убийство?

Р.: И каждый раз вот так.

$\ldots$

И.: А последнее что было?

Р.: Последнее... последнее убил.

И.: Ммм.

Р.: В лесопосадке. Горло ему перерезал.

И.: За что?

Р.: За что... он малолеток... мне все равно... (неразборчиво).

И.: Малолеток? Поняла я, наверное, неправильно...

Р.: Я говорю, малолеток насиловал...

И.: А, молодых насиловал? Каких? Девочек? Мальчиков?

Р.: Мальчиков. Девочек.

И.: Ммм. Ну, расскажите подробнее, как это произошло?

P.: Ну, в лесу пили... такой шалаш сделали аккуратный... Вон там пили.

Потом я начал у него допытывать: ты за че насиловал? Он начал...

Я взял бутылку, разбил о голову...

И.: О голову?

Р.: Да. Мы вдвоем были, потом его отнесли в лес, ну, где гуща...

И.: Ммм.

Р.: Где народу меньше. Там мы его, короче, кончили... вдвоем.

И.: Вдвоем. Ясно. И какой срок дали?

Р.: 10. А нет, 14.

И.: Ммм.

Р.:(Вздыхает). 
Ситуация беседы с самого начала была очень напряженной. У меня никак не получалось хоть как-то разговорить Павла. Он продолжал смотреть в стену, глубоко вздыхать и плакать. Я почувствовала острую беспомощность. Попытки найти какие-то ресурсы в прошлом опыте не увенчались успехом. Я продолжала подсказывать ответы, которые мешали моему собеседнику чувствовать себя более свободно.

На этом месте стоит остановиться подробнее. Мои внутренние сомнения в нужности/возможности продолжения беседы, вероятно, проявлялись через мои телесные знаки. В какой-то момент мой взгляд сфокусировался на его палке, на которую он, сидя, опирался и периодически постукивал в такт молчанию, своим внутренним мыслям и воспоминаниям. Быстро, не задерживаясь промелькнула мысль: «Вот скажу что-то не так, стукнет и все...». После интервью мне за эту мысль больше всего было стыдно...

Позже история его последнего убийства всплывет в разговоре еще несколько раз, я должна была понять, почувствовать, что в этом факте скрывается что-то крайне важное для Павла.

P.: Я вот в (таком- то году) освободился, поехал в Удмуртию. Там я пожил нормально.

И.: Долго?

Р.: Долго. Там все родственники. И все татары. Все гостеприимные.

И.: Ммм. Хорошо. А потом что?

P.: Потом че, уехал в(эту область)... чтобы этого убить... Убить надо было.

И.: Кого?

Р.: Этого педофила.

И.: Ммм. Откуда вы о нем знали?

P.: Я его знал... Где он находится, где работал: все знал!

$\ldots$

И.: А откуда вы его знали?

Р.: Так мимолетом... Но я знал, что он - пидор.

И.: А откуда? Кто-то рассказал? То есть у вас история была какая-то? ... А это с предыдущей колонии, что ли? ... Вы до этого то есть вместе сидели, что ли, с ним? А почему его надо было убить?

P.: Не должен был... жить просто.

И.: Ммм. Ну, как это все? То есть вы приехали в (эту область) и вот вы его искали?

P.: Нашел я его сразу. Купили вина, водки... пошли в лесопосадку, где я его оглушил.

И.: Это в каком году было?

P.: (молчание). 6 лет тому назад.

И.: Ммм. И вас нашли сразу?

Р.:Да.

И.: А как вы объяснили? Когда дознание идет же, надо как-то объяснить Свой поступок?

P.: Объяснил, конечно, убил я. 
И.: Признались?

Р.: Да (молчание). Все меня закинули, повезли (тишина, долгая пауза).

И.: А все-таки, почему его надо было убить? То есть он вас обидел, что ли, в этом ...

Р.: Нет. Он меня не обидел. Он мне... (всхлип) в душу насрал...

И.: Ммм...

Р.:(молчание).

И.: Кого-то из родственников обидел, что ли?

P.: Нет.

И.: А что произошло? Не можете рассказать?

P.:(молчание). Он изнасиловал...

И.:...Ммм...

Р.: (всхлип) Молодых девок...

И.....И вы об этом узнали, да?

Р.: Да. Я его сразу нашел.

И.: А это кто-то о нем рассказал, это как история его? Откуда вы узнали, что он насиловал?

P.: (долгое молчание).

И.: Тяжело, конечно, это пережить, я понимаю.

Р.: Да я уже (всхлип)... я уже пережил.

Скажу сразу, мне так и не удалось понять, что же произошло с Павлом в колонии: почему он стал намеренно разыскивать сидевшего с ним в колонии человека, специально поехал в другую область, чтобы совершить задуманное, как, из каких источников узнал адрес? Стоит отметить, что не так важно было понять мотивы отдельного, конкретного убийства, совершенного этим человеком - это не входило в задачи проекта. Собственно и в других проектах, посвященных тюремному опыту, вопросы о соответствии рассказа о совершенном преступлении «реальности», или адекватность приговора и полученного срока, доказательства вины или невиновности интересовали нас в той мере, в какой эти нарративы работали в направлении нормализации индивидуального опыта, аргументации смысла совершенного для встраивания этого отрезка жизни в контекст биографии в целом. В разных историях жизни, сопряженных с тюрьмой, мы старались обнаружить следы самой российской системы наказания в ее современном варианте: с ее смыслами, особыми режимами власти, практиками изоляции, лишений и унижений, полной ликвидацией приватного пространства, красными и черными иерархиями (включая гендерные режимы, межэтнические и межрелигиозные отношения) и соответствующими статусами отбывающих свои сроки заключенных (Омельченко, 2016).

Понимание места и позиции человека внутри этой системы было важно не только для реконструирования его или ее индивидуальной судьбы, но и для сборки общей картины функционирования пространства тюрьмы как концентрированного выражения ключевых тенденций современного российского общества в целом. Это не значит, что для нас остается 
незначимой личная история преступления и наказания, но мы точно отходим в сторону от вынесения некоего морального или гражданского вердикта в отношении тяжести/недопустимости/бесчеловечности совершенного проступка. Мне уже в ходе интервью было в принципе понятно, что за этой практически нерассказанной историей Павла стоит важный сюжет, имеющий отношение к тюремной иерархии, что самым непосредственным образом было связано с исследовательским вопросом. Однако пробиться сквозь тягостное молчание, кашель, всхлипывания и слезы собеседника мне так и не удалось. Самым первым впечатлением от всей ситуации было то, что он сам испытал унижение сексуального характера - не обязательно будучи в позиции обиженного - a, например, мог подвергаться особого рода издевательствам. Другой вариант - что он исполнял чей-то прямой заказ на убийство этого человека, будучи включен и после отсидки в широкие информационные сети, связывавшие заключенных и освободившихся в систему взаимного оповещения. Так, например, не отданный карточный долг или нереализованное наказание внутри колонии за караемый поступок (насилие со стороны «актива, козлов» ${ }^{7}$, сокрытие своего гомосексуального прошлого или изнасилования несовершеннолетних) могли преследовать бывшего зэка и на свободе. Поскольку текст интервью не позволяет идти дальше предположений и догадок, этот сюжет остается без объяснения.

Несколько раз по ходу интервью я пыталась остановить разговор, спрашивала: «Вам не тяжело разговаривать?» - и всякий раз он отвечал, что нет, что готов рассказывать, только не очень понимает, что я от него хочу, чего жду, о чем рассказывать? Сейчас, уже в который раз перечитывая транскрипт и вспоминая само интервью, я натыкаюсь на места, которые по всем законам «жанра» следовало развернуть, раскрыть, я же продолжала, задавая вопросы, предлагать свои ответы, которые я, вероятно, выхватывала автоматически из прошлого опыта исследований. Очевидно, что меня тяготили длинные паузы и постоянные всхлипывания информанта, мешали ощущения, что беседа топчется на одном месте, казалось, что я практически клещами вытягиваю ответы, резонирующие с моим опытом. С одной стороны, это можно оправдать сложностью ситуации и закрытостью информанта, однако мне до сих кажется, что Павел очень хотел поделиться и рассказать, а у меня не хватило смелости или терпения дождаться его собственной истории. И, вероятно, вся обстановка, мое напряжение, плач и стоны информанта подталкивали меня (и это было видно) к завершению тягостной для обоих беседы.

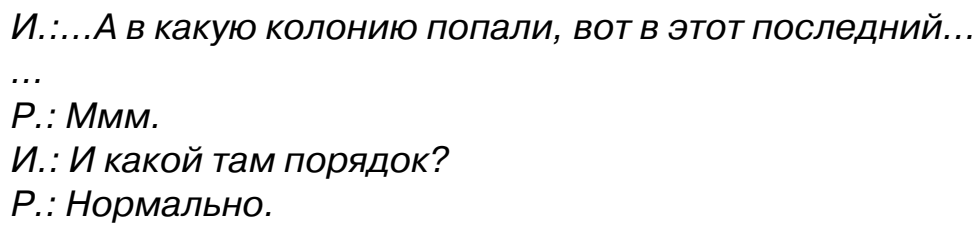

7 Члены актива, или «козлы» - так называют заключенных, которые подписывают с администрацией согласие на сотрудничество, и становятся активной, часто крайне агрессивной частью неформальной системы тюремного режима. 
И.: Ну, она какая считается - черная или красная?

Р.: Черная.

И.: Черная? То есть воровской порядок?

Р.: Не воровской... так

И.: Ну, а как вы его называли?

Р.: Мы его никак не называли... это как ты назовешь.

И.: Ммм. Ну, колонии же разные, бывают и красные.

Р.: А это не красная.

И.: Не красная, нет. Вам не тяжело разговаривать?

Р.: А че не пьете? (шуршание фантика от конфет)... (пьет чай).

И.: Ну, вот мы изучаем, нам интересно, как отношения складываются в тюрьме, в последней вашей (номер колонии), можете рассказать? Чья власть, как вот, это вот, отношения складываются с другими? Кто главный, кто подчиненный?

Р.: Главный - хозяин. Все он решает.

И.: Хозяин - вор? Или...

P.: Нет.

И.: Начальник?

Р.: Начальник... Он решает сколько, че... (кашляет, долгая пауза).

И.: А актив есть? Был актив?

Р.: да... (отхлебывает чай).

Совсем уж странная моя ошибка - что я отказалась от чая с конфетами, которые в самом начале беседы предложил Сергей сначала Павлу, потом мне. Чай он заварил как положено - не пакетиками, а насыпал листовую заварку прямо в прозрачную чашку. Было видно, что это хороший чай, правильный. Чай вместе с сигаретами остается самой ходовой валютой в колонии, ими по-прежнему расплачиваются за грязную работу, к которой привлекают как тех, кто не греется, так и обиженных (мытье санузлов, стирка одежды, мытье полов, уборка помещений). Чай в колонии, особенно мужской, пьют постоянно - когда ведут бесконечные беседы, играют в карты, разбираются с конфликтами. Было видно, что Павел пьет с особым удовольствием. И, может быть, включись я в этот знакомый ему ритуал - беседа бы пошла по-другому. По крайней мере, длинные паузы были бы вполне оправданы...

После получасового разговора я вдруг вспомнила, что еще ничего не узнала про самого Павла.

И.: А вам сколько лет?

$P .: 54$.

И.: 54? А образование какое увас?

P.: Одиннадцать.

И.: 11 классов? (помехи). А специальность какая-то была? Что вы делали, работали?

P.: (кашель и тишина)... даже рассказать не о чем...

И.: $A$ ? 


\section{Р.: Даже рассказать не о чем.}

И.: Почему? Ну, это же ваша жизнь...что вы помните, расскажите.

Р.: (пьет чай, отхлебывает). Тишина.

И.: Семья? Была у вас семья?

Р.:Да.

И.: А сейчас?

P.: (пьет чай) Сейчас нету.

И.: А сами откуда? Здесь? Местный?

Р.: Казахстан.

И.: А, из Казахстана? А по национальности? Русский?

Р.: Нет, мариец.

И.: Мариец? Ммм.

Р.: (отхлебывает чай).

И.: А были еще... или вы не знаете - в колонии марийцы?

Р.: Были.

И.: Были? Какое-то землячество делали, нет?

Р.: Бывало (отхлебывает чай).

И.:...Вопросы решать... помогали?

Р.: Да (чай отхлебывает громко).

И.: Ммм.

P.: (тишина).

И.: Тяжело вспоминать или что?

\section{Р.: Ничего не идет в голову.}

Павел рассказал, что сам он был «не при власти... себя так не вел...», особых нарушений не было, сам себя определяет как пацана (то есть мужика $\left.{ }^{8}\right)$, работал на промзоне, везде - «сучки рубил и лес». А на мой вопрос, как называли в колонии авторитетов - блатных, он ответил, что их называли «свои и по именам». Я уточнила, были ли какие-то особые отношения со стороны осужденных или администрации к людям разных национальностей. Павел отвечал, что особой разницы не было: все сидели за разное: «за убийство. Кто за че. Кто за наркотики», вели они себя нормально и относились к ним «нормально, как себя поведешь. Как себя покажешь - так оно и есть». Правда, говорит, что было и такое, что некоторых из них заставляли убирать за кем-то, чистить (он говорил в этом месте о таджиках): «Ну, заставляют, не заставляют, а как... (пауза) их просят, они делают тоже.

И.: Ааа. Ну, платили чем-то?

Р.: Платили сигаретами и этими... чаем.

Я уточнила, навещал ли его кто-то, он сказал: «У меня мать, когда еще была жива, навещала».

8 Мужик - это средняя позиция внутри тюремной иерархии: не в активе и не в блатной структуре. Мужикам разрешалось работать и подавать на Удо (что совершенно недопустимо для блатных и авторитетов в черных колониях). При этом мужики оставались основной рабочей силой, которую использовали и администрация, и воровские («черные») начальники. 


\section{И.: Ммм.}

Р.: (пьет чай, отхлебывает чай).

И.: А как... на свободе вообще удавалась пожить? Или нет? Были у вас перерывы?

Р.: Мало.

И.: Мало, да? (молчание). А как так получилось?

Р.: Я не знаю.

И.: Алкоголь или что?

Р.: И это тоже...(тишина).

В краткой истории про игры в карты в колонии Павел рассказал, что играли на большие деньги, на кону могли быть и пять, шесть и больше тысяч, играть могли несколько дней подряд, проигравших наказывали, «ставили на счетчик». В колонию вольные «заносили телефоны» и алкоголь, достать который (как и наркотики) не было проблемой. Например, он рассказал, как они в колонии праздновали Новый год, «развешивали всякую мишуру, играли в детские игры, пили». На мои вопросы о том, как он попал в этот реабилитационный центр, Павел сказал, что «сюда... я... старики, которые уже... никакой..., тяжело ходить совсем, и меня отпустили как... они закрыли, допустим, вот сюда в лечебницу... Ну, как пенсионный здесь...».

В ходе беседы встал вопрос о статусе обиженных в колонии. Именно им («обижалкам»), по мнению информанта, приходится хуже всего:

И.: А много их было там?

Р.: Ну, человек 100 где-то. Где-то человек 50.

И.: Ммм. А кто туда попадал, в обиженные?

P.: Определяли сами... сами говорили.

И.: Ну, кто-то сам говорил, а кого-то определяли? Да?

Р.: Да.

И.: А за что?

Р.: За разное хулиганство. ... Че-то пообещал и не сделал. ... Ну, денег, например.

И.: Ну, жестко. И с ними общаться нельзя?

Р.: Можно, смотря как.

И.: Как?

Р.: Чтоб меньше народу видело.

И.: Ааа, понятно. И еще, наверное, за секс, да? А были, которые не сами, например, а насилие какое-то над ними?

Р.: Это уже... уже специально делали.

И.: Специально делали? Ну, просто какую-то историю, если можете вспомнить?

P.: Попали или че.

И.: В смысле попали?

P.: Ну, пообещали - не сделали.

И.: Ммм. И могли изнасиловать, что ли? 
Р.: Изнасиловать - смотря за че.

И.: Ммм. И как к этому относились другие осужденные? Не защищали? Нельзя защищать?

P.: Нет.

И.: Почему?

Р.: Как я полезу в чужой бардак?

И.: Ммм.

P.: (молчание).

И.: Ну, жалко же, наверное, человека?

Р.: А че сделаешь?

И.: Ясно. И че заставляли делать? Они какую-то особую работу делали или что?

Р.: Ну, их заставляли все делать.

И.: Ну, например?

P.: Ну, например, обувь чистить или че.

И.: Стирать?

Р.: Да, стирать.

И.: Дааа... сложно.

Р.: У вас... (вздох или плач?)

И.: Что?

Р.: Разговор плохо клеится (плачет).

И.: Че разговор какой? (не расслышано)... немножко...

Р.: Плохо клеится.

И.: Полный кризис. Да? Не расстраивайтесь. Ну, сейчас вам здесь помогут. Здесь люди хорошие очень. Вы - молодой мужчина еще, поправитесь.

P.: Уже не могут поправить (длинная пауза, кашляет и плачет).

И.: А родные остались какие-то у вас?

P.: У меня только один я.

Интересно, что в какой-то момент Павел даже пытается мне помочь, на что я обратила внимание только сейчас, читая транскрипт. Он хотел поговорить еще, но «разговор наш плохо клеился»... Я не буду в очередной раз перечислять свои ошибки в последнем отрывке разговора. Ясно, что мне стоило дать возможность рассказать его историю, а не рассказывать все самой. Но самый сильный сюжет ожидал меня в самом конце беседы.

И.: А были еще такие в колонии... тоже история известная же, да? История каждого известна.

Р.: Да (молчание).

И.: Не было?

P.: (глубокий вздох и звук, будто пьет чай, возможно).

И.: Или не знаете?

Р.: Я понял... 

И.: Были, да?
Р.: Че только не повидал!
И.: Ммм.
Р.: Жизнь... даже 10 лет назад, пора простить...
И.: Ммм. Простить? Я не поняла. Или просить?
Р.: (плач, всхлип, кашель).
И.: Ну, ладно, спасибо большое, отдыхайте, а то уже немножко мы...

\section{Р.: Я ничем (громкий всхлип) вам не помог...}

Так закончилось это интервью. Я не случайно вынесла последнюю фразу информанта в название статьи-эссе. Именно эти слова звучали в моей голове весь обратный путь из этого реабилитационного центра - назад, в областной город. Именно они подтолкнули меня к написанию этого текста. Вероятно, меня можно упрекнуть в излишней драматизации ситуации или в том, что я ищу какой-то другой, скрытый смысл в этой фразе. Но мне до сих пор кажется, что Павел хотел мне помочь в моей работе, принести хоть какую-то пользу. В нашей профессиональной этике существует принцип, важный в данном случае: интервью для информанта должно стать значимым фактом дня, неким подтверждением, пусть и временным, какой-то значимости и важности его или ее истории жизни, вызванным не показным любопытством, а поддерживаемым в ходе беседы сбалансированным общением человека с человеком.

На этот раз мне это явно не удалось. И еще одно. Размышляя над этим исследовательским опытом, я поймала себя на том, что почувствовала облегчение, уходя из этого центра. Меня больше тревожили совершенные ошибки, чем, собственно, сама тяжелая жизненная история человека, который, как и многие другие в этом центре, оказался никому не нужным. В ходе работы над этим эссе мне стало легче, получился своего рода бесплатный сеанс самотерапии. Думаю, что это поможет в дальнейшем оставаться более сенситивной в исследовательском поле и, решая важные задачи исследования, не терять способности к сопереживанию другим, пусть и, как в данном случае, другим с такими фактами биографий, которые очень трудно понять, разделить и принять.

\section{Литература}

Гудова Е. А. О «травме методом» и эмоциональной работе полевого исследователя // Социология: методология, методы, математическое моделирование (4М). 2019. № 48. С. 58-82.

До и после тюрьмы. Женские истории / Под науч. ред. Е. Л. Омельченко. СПб.: Алетейя, 2012.

Около тюрьмы: женские сети поддержки заключенных / Под ред. Е. Л. Омельченко, Дж. Пэллот. СПб.: Алетейя, 2015.

Омельченко Е. Л. Красные и черные: гендерное измерение структур различия и исключения в мужских колониях // Журнал социологии и социальной антропологии. 2016. T. XIX. № 2. C. $142-159$. 


\section{"I didn't help you in any way...": Research Reflection After a Failed Interview}

DOI: $10.19181 /$ inter.2020.21.5

\section{Elena Omelchenko}

Omelchenko Elena - Doctor of Sociology, Professor, Director of the Centre for Youth Studies, HSE University - St. Petersburg, omelchenkoe@mail.ru.

The article discusses the complex and critical moments of interfacing and / or mismatch of ethical and professional principles and skills of the sociologist that occur during the fieldwork concerning difficult, sensitive issues. The balance of permissible boundaries of intrusion into the personal spaces and the principles of voluntariness may conflict with the researcher's obligations during the interview, and possible risks for the informant - with the preservation of the safe (physical, psychological) space of the researcher. This conflict is considered as part of the sociologist's emotional work in the course of direct communication with informants, as well as the experience and reflection before and after the conversation, that constructs sociologist's professional identity as a whole. The article critically examines the permissible limit of the researcher's impartiality, the ability to breed personal and professional "Self" in the study of vulnerable (dependent) group or individual in difficult life situation. In this article, we are talking about life experience research of people undergoing rehabilitation (physical, psychological, social) in one of the public centers (NGOs) to help people recently released from local colony and found themselves in extreme social loneliness.

Keywords: emotional work; sensitive field; life experience; vulnerable group's research

\section{References}

Gudova E. A. (2019) O "travme metodom" i emocional'noj rabote polevogo issledovatelya [On "Trauma by Method" and Fieldworker's Emotional Work]. Sociologiya: metodologiya, metody, matematicheskoe modelirovanie (4M) [Sociology: Methodology, Methods, Mathematical Modeling]. No. 48. P. 58-82.

Omel'chenko E.L. (2016) Krasnye i chernye: gendernoe izmerenie struktur razlichiya i isklyucheniya v muzhskih koloniyah [Red and Black: the Gender Dimension of the Difference and Exclusion Structures in the Male Colonies]. Zhurnal sociologii $i$ social'noj antropologii [The Journal of Sociology and Social Anthropology]. Vol. XIX. No. 2. P. 142-159.

Omel'chenko E.L. (ed.) (2012) Do i posle tyur'my. Zhenskie istorii [Before and After Prison. Women's Stories]. SPb.: Aletejya, 2012.

Omel'chenko E.L., Pellot J. (eds.) (2015) Okolo tyur'my: zhenskie seti podderzhki zaklyuchennyh [Near the Prison: Women's Support Networks for Prisoners]. SPb.: Aletejya, 2015.

Received: 15.01 .2020 